as the disease has become more fully developed, and one has felt one's utter helplessness to relieve more than temporarily the dreadfal suffering one has had to witness, and I-for oneand $I \mathrm{am}$ sure that in this my feelings are shared not only by medical men, but also by those who have had to watch and wait whilst such scenes were going on, and that any remedy that promises results even far less favourable than those claimed for this method of treatment should be placed at the disposal of those who have to do battle with this terrible disease. We must improve the sanitary conditions and the general surroundings of those who are most liable to the disease, in order to prevent the disease or to keep it at as low a limit as possible, but we have also a duty to perform to those who are actually smitten down.

[In conclusion, Dr. Woodhead drew attention to the muniscence of the Worshipful Goldsmiths' Company and the public spirit that has actuated the members of the Metropolitan Asylums Board.]

\section{THE PREPARATION OF BEHRING'S DIPHTHERIA ANTITOXIN.}

BY F. KLEIN, M.D., F.R.S.

WITH the view of enabling those who are engaged in preparing from the horse Behring's antitoxin to obtain it in a much shorter time than the present methods permit, I take this opportunity of publishing the following notes.

I have been carrying out for the Medical Department of the Local Government Board a series of experiments that gave for their object study of the preparation and of the nature of Behring's antitoxin. The rationale of the method ased by Ronx ${ }^{1}$ for obtaining from the horse Behring's antitoxin seems to me difficult of acceptance from a theoretical point. This does not, of course, imply that the serum which Roux obtains has not the antitoxic power which he claims for it The numerous experiments described by him ${ }^{2}$ as made on the guinea-pig, and particularly his striking curative results on the human subject, can leave no doubt as to this. What seems to me the chief difficulty of his method is that horses require in his process a very long and tedious series of numerous injections, some direct into the vessels, with enormous quantities of pure diphtheria toxin (sometimes $200 \mathrm{c}$ c. of pure toxin in a single injection), for the production by them of serum of considerable antitoxic power. Roux explains his procedure by assuming that by injection of increasing quantities of pure strong toxin the tissues of the arse are again and again stimulated and sustained in their formation (secretion) of antitoxin.

In all infectious diseases the degree of resistance to a given disease acquired by one or more previous infections rests with the blood and the tissues. In some of the infectious diseases-e g., small-pox, scarlet fever, and anthrax-this condition of resistance against a fresh infection amounts to lmost complete immunity. This condition of resistance is Wrought about by and (as far as we know at present) depends on the growth and life processes of the specific microbe in the infected body during the antecedent attacks, whether natural or experimental. The precise manner, however, in which this condition of resistance is created is as yet not clearly made out. Varions views have been put forward to explain it, which it is not necessary to enter into here; they are all (including Roux's) based more or less on assumptions. The chief facts experimentally established by the researches of Behring, Kitasato, R. Pfeiffer, Wassermann, and others are-that the blood of an animal which has acquired immunity possesses antitoxic property, that the degree of antitoxic property of the blood stands in direct relation to the degree of resistance acquired by the animal furnishing it, and, further, that this antitoxic property of the blood not only renders the particular animal capable of overcoming and of withstanding the disease that is in question, but also other animals into which it is introduced. In the case of the sheep and goat, Behring has shown that it is possible by repeated diphtheria injections to render these animals gradually highly tolerant against diphtheria, and at the same time to confer on their blood a suigh degree of antitoxic power. By virtue of this antitoxic condition of their blood small amounts of the blood serum are capable of protecting guinea-pigs against inoculation of diphtheria bacillus, and of neatralising in these animals the diphtheria toxin if it be injected. The two substances-

1 Uescribed in the Annales de l'Institut Pasteur, September, 1894. toxin and antitoxin-are, then, in their proper proportions, mutually antagonistic.

Now, Roux, as I have said, introduces over and over again large amounts of pure diphtheria toxin into a horse, which has already by previous injections of the pure toxin been rendered to a certain extent resistant against this toxin (it is because of this resistance that he finds it necessary to increase the dose of the toxin)-that is to say, a horse that has by previous injections of diphtheria toxin become more or less resistant must possess a corresponding amount of antitoxin in its blood. But since the two substances-viz., toxin and antitoxin-are antagonistic and neutralise one another it follows that each successive injection of a large quantity of pure diphtheria toxin into a given horse must neutralise a proportionate amount of antitoxin already formed and present in the blood of the animal. This possibly explains the extraordinarily long time which Roux's horses take before their blood is rendered suffciently antitoxic. These considerations led me to adopt a different plan in the preparation of antitoxin serum from the horse-a plan, indeed, which corresponds more closely than Roux's to the natural process. By this plan I have succeeded in obtaining from the horse antitoxic serum in a far shorter time than is possible by Roux's plan; and, as observation proves, this serum is possessed of considerable antitozic power. The principle of my method is as follows. By a few injections of attenuated living bacilli-the attenuation is due to age of the culture-along with their toxin into the horse, this animal is furnished with a certain degree of resistance. Next, large quantities of living diphtheria bacilli (minus their tozin), taken from the surface of solid cultures of gradually increasing virulence, are repeatedly injected subcntaneously, so as to allow the bacilli to grow and to multiply, and to gradually produce within the body of the animal, as is the case in the natural order of things, the toxin, and ultimately the antitoxin.

Every such injection on my plan is followed by a temporary reaction, a rise of temperature varying between $0.6^{\circ}$ and $1.8^{\circ} \mathrm{C}$, and a local tumour; but there is no suppuration at the seat of inoculation. As soon as one such tumour has disappeared a new injection is made, as stated above, with large quantities of living bacilli scraped from the surface of solid media (agar and gelatine). By the third week the animal will bear the scrapings from the surface of two whole agar cultures of virulent character. In the case of one horse I, by this method, obtained antitoxic serum in twenty-three days, in another horse in twenty-six days, from the date of the first injection. If after the first bleeding of the horse it be again twice or thrice injected with virulent living bacilli (taken from the surface cultures) the further serum obtained from such horse possesses even increased antitoxic power.

The antitoxic power of the serum in the twenty-three and the twenty-six days' horse was tested on guinea-pigs, and it was found that one part of serum was capable of protecting from 20,000 to 40,000 grammes body weight of guinea-pig against the living bacilli and toxin (not merely against pure toxin), considerably more than a fatal dose of living bacilli having been injected. This serum has been used in cases of diphtheria on the human subject-some of them very severe cases. It was injected in doses of from 5 c.c. to 8 or 10 c.c. and in severe cases the injection was repeated within twentyfour hours. The result was highly satisfactory. In some severe cases it was particularly striking, the further spread of membrane being entirely arrested, and rapid loosening and discharge of the existing membrane being also a conspicuons feature.

\section{TWO CASES OF OVARIOTOMY PERFORMED TWICE ON THE SAME PATIENT.}

BY ALBAN DORAN, F.R.C.S. ENG., SURGEON TO THE SAMARITAN TREE HOSPITAI.

IN the summer of 1894, within the space of three weeks, I performed ovariotomy upon two patients who had already undergone that operation. The necessity of removing the remaining ovary, even should it appear healthy, when an ovarian cyst or tumour is extirpated has been strongly urged by certain authorities. Hence second operations on the same subject are worth consideration.

I This paper is based on the specimen of papilloma figured below, which was exhibited for its clinical features at a m London Iledico-Chirurgical Society, Dec. 7 th, 1894. 